\title{
Associations between substance use and type of crime in prisoners with substance use problems - a focus on violence and fatal violence
}

This article was published in the following Dove Press journal: Substance Abuse and Rehabilitation

\section{Anders Håkansson \\ Virginia Jesionowska}

Department of Clinical Sciences Lund, Psychiatry, Faculty of Medicine, Lund University, Lund, Sweden
Correspondence: Anders Håkansson Department of Clinical Sciences Lund, Psychiatry, Malmö Addiction Center, Södra Förstadsgatan 35, plan 4, S-20502 Malmö, Sweden

Email anders_c.hakansson@med.lu.se
Aim: The present study aimed to study the associations between substance use patterns and types of crimes in prisoners with substance use problems, and specifically whether substance use patterns were different in violent offenders.

Methods: Interview data of prisoners with substance use problems $(\mathrm{N}=4,202$, mean age 33.5 years, SD 9.8), derived from the Addiction Severity Index, were run against criminal register data on main types of crimes in the verdict.

Results: In binary analyses, compared to those with acquisitive and drug crimes, violent offenders had lower prevalence of illicit drugs and homelessness, but higher prevalence of binge drinking, and higher prevalence of sedative use than clients sentenced with drug crimes. Clients with violent crime had lower prevalence of injecting drug use, compared to all other crimes. In logistic regression, binge drinking and sedatives were positively associated with violent crime (as opposed to non-violent crime), whereas heroin, amphetamine, cocaine, and injecting drug use were negatively associated with violent crime. Among violent offenders only, sedatives tended to be associated with fatal violence ( $p=0.06$ ), whereas amphetamine, homelessness, age, and (marginally significant, $p=0.05$ ) heroin were negatively associated with fatal violence, as opposed to non-fatal violence.

Conclusion: Treatment and risk assessment in violent perpetrators with substance use may need to address sedatives and alcohol specifically. Limitations of the study are due to self-reported and cross-sectional data and because a large majority of the prison sample studied here are men. Keywords: Addiction Severity Index, prison, criminal justice, violence, substance use disorder, alcohol, sedatives

\section{Introduction}

Crime and substance use are known to be closely associated, ${ }^{1}$ and substance use disorders are common in criminal justice settings; in a systematic review of studies in prison populations, alcohol abuse and dependence were reported in $18 \%-30 \%$ of males and $10 \%-24 \%$ of females, whereas drug abuse and dependence were reported in $10 \%-48 \%$ and $30 \%-60 \%$ of male and female clients, respectively. ${ }^{2}$ Also, substance use disorders are known to be associated with violent crimes..$^{3-8}$

Violent crime, including violent assault, homicide, manslaughter, or serious threats, intuitively causes great suffering and harm to the society, and among causes of deaths in populations of illicit drug users with criminal behavior, physical assault from others represents a significant minority of deaths. ${ }^{9,10}$ Also, in data from the present setting, violent crime has been shown to be associated with a high degree of psychiatric problems including substance use disorders, indicating large treatment needs in 
this population which may call for specific interventions in comparison to other crimes. ${ }^{11}$ Previous data, from the general male population of the setting assessed here, demonstrated that psychiatric disorders in early adulthood predict violent crime and that a substance use disorder is one of the strongest predictors. ${ }^{12}$

Thus, alcohol and drug use disorders confer an additional risk over and above the risk related to other mental disorders, ${ }^{13}$ relapse into violent crime is high, and data indicate that inprison treatment of substance use disorders as a group may reduce violent recidivism. ${ }^{14}$ However, it has been argued in the literature that a lot remains to be understood in the relationship between substance-specific substance use problems and violent crime. ${ }^{7}$ While substance use disorders as a group constitute a risk factor, substances typically misused are highly diverse. Drugs of misuse, such as in the present setting, range from central stimulants, causing euphoria, psychomotor activation, and possibly psychotic symptoms, ${ }^{15}$ to benzodiazepines, possibly causing disinhibition and misused either recreationally or for self-medicating purposes. ${ }^{16}$ In the present setting, among the criminal justice clients with substance use problems, amphetamine, cannabis, alcohol, and a polydrug use pattern traditionally have played an important role, while opioids constitute a significant but traditionally less prevalent problem. ${ }^{17,18}$ Given the prevalence of substance use disorders in clients with criminal behavior, populations of clients sentenced to prison are likely to include many clients needing structured assessment and treatment of their substance use-related diagnoses.

Also, many crimes committed by substance users are categorized as drug crimes, as they involve either the use or handling of illicit drugs, or as acquisitive crimes such as stealing, shoplifting, or burglary, related to the need to finance drug use. ${ }^{19}$ For example, acquisitive crimes committed by drug users appear to decrease after substance use disorder treatment. ${ }^{20}$ Perpetrators of violent crime may differ from subjects committing these other drug-related crimes and may display different treatment needs.

Thus, based on high prevalence of substance use disorders in subjects with violent behavior, and the relative paucity of studies providing substance-specific data in relation to violent crime, in the present study, we aimed to describe how substance use patterns differ between substance-using prisoners across different types of crimes, and with a focus on violent crime, we aimed to compare perpetrators of violent and fatally violent crime to clients with other types of crime.

\section{Methods \\ Data sources and analysis sample}

The present study was a cross-sectional analysis of the association between the substance use pattern and the type of crime in adult clients (18-66 years of age) with substance use problems assessed with the Addiction Severity Index (ASI) in the Swedish prison system. The study is based on ASI interviews carried out by criminal justice staff in Swedish prisons from 2001 to 2006. From 2001, the ASI was increasingly implemented as a tool for assessment of substance use and substance-related problems, ${ }^{21}$ and an increasing number of units within the Swedish Prison and Probation Service started using the instrument, mainly in units specialized in clients with substance use disorders. The ASI was used for assessment of severity, treatment allocation, and for followup and research purposes. Since the present database was blinded and delivered to our research group in 2006, a number of papers have been published based on this data material, including predictions of drug-related mortality ${ }^{9,10}$ and criminal recidivism. ${ }^{22}$ The ASI is a well-documented instrument used worldwide for the assessment of substance use problems, and it has become a standard instrument for assessment of substance use in clinical situation and in research settings. ${ }^{23-25}$ At one given time point in close connection to the study period, around 5,500 individuals in Sweden were in prison. Among criminal justice clients, the ASI project in the criminal justice system aimed to address subjects with problem use of alcohol and drugs, and the use of the ASI interview was gradually increased during the study period and expanded to an increasing number of prisons, primarily units with a focus on substance use disorders. In a previous post hoc attrition analysis, interviewers who carried out more than 30 interviews in the project were addressed, and they reported that approximately six percent of the clients approached for an interview refused it. ${ }^{17}$

The whole dataset used here contains data from 7,085 clients assessed for substance use problems in different criminal justice settings. Here, in order to study clients with a criminal record specifically involving prison sentence, clients interviews in prison $(\mathrm{N}=5,122)$ were included. Among them, 27 clients instead had been interviewed with a slightly different instrument adapted for adolescent populations (Adolescent Drug Abuse Diagnosis instrument ${ }^{26}$ ) and were excluded for that reason. Among the remaining clients (all above 18 years of age), clients were excluded if they interrupted the interview or were judged by the interviewer in any domain of the instrument to have problems understanding or 
suspected misrepresentation when answering the questions. Also, in order to analyze clients with a confirmed substance use problem, clients were excluded if the dominating drug of abuse was reported to be "none" or "missing", leaving 4,254 clients. Among them, in 52 cases, criminal justice registry data for the type of crime of the verdict were missing, and these clients were also excluded. Thus, the final cohort consisted of 4,202 individuals. Clients were predominantly male $(n=3,788,90 \%)$ and the mean age was 33.5 years (SD 9.8 , median 32 years, range 18-66).

\section{Study variables}

The main type of crime in the verdict was retrieved from the Swedish criminal justice register. Here, crimes were divided into four categories: violent crimes, acquisitive crimes, drug crimes, and others. Acquisitive crimes refer to thefts and robberies, including selling of stolen goods. The type of crime refers to the main (most severe) crime in the verdict, such that these categories of crime are mutually exclusive. Violent crimes include murder, manslaughter, assault, and threats.

Based on the ASI assessment, the most common primary drugs reported in the present cohort (mutually exclusive) were amphetamine $(32 \%)$, polydrug use (defined as two or more drugs concomitantly, 17\%), alcohol (13\%), cannabis (13\%), heroin $(9 \%)$, alcohol and drugs combined (7\%), sedatives $(3 \%)$, and cocaine $(3 \%)$. In the present analysis, variables included describe problem drug use of a substance for at least six months. Problem substance use, for at least six months followed the ASI assessment: alcohol binge drinking (46\% of included subjects), heroin (22\%), other opioids (15\%), sedatives $(36 \%)$, amphetamine $(64 \%)$, cocaine (16\%), cannabis $(62 \%)$, and injecting drug use (53\%).

Clients were assessed with the ASI interview after a median of 27 days after arrival to the prison unit where the interview took place (mean 63 days), and altogether, 93\% were assessed during the first six months at that unit and 97\% within the first year. The study was approved by the Regional Ethics Committee, Lund, Sweden (file number 2011/272). As no personal data were identified in this study, each participant's written informed consent was deemed not required by the Regional Ethics Committee.

\section{Statistical analysis}

In the descriptive analysis, substance use and other characteristics (history of psychiatric hospitalization and demographic data) were compared across major groups of crime (violent crime, drug crime, acquisitive crime, and all other crimes). Chi-square tests were used to examine differences between violent crime and each of the other categories. Also, within the subset of clients with a violent main crime, binary comparison was carried out for the same variables, between perpetrators of fatal $(n=164)$ and non-fatal $(n=546)$ crimes, respectively. Also, all variables were entered in a logistic regression (direct, non-stepwise mode), in order to identify variables associated with violent crime compared to all other crimes, and likewise, all variables were entered in another logistic regression that identified variables associated with fatal violence compared to non-fatal violence. In order to assess the risk of multicollinearity, a correlation matrix was run for all assessed variables (variables included in Tables 1-4), with a predefined limit of Pearson correlation set at $0.7 .{ }^{27}$ Here, the highest correlations were for amphetamine and injecting drug use and for sedatives and other opioids (Pearson correlations of 0.50 and 0.32 , respectively), whereas other correlations were below 0.30 and most very low.

\section{Results \\ Descriptive findings of substance use, psychiatric hospitalization, and demographics by type of crime}

Primary crimes included in the verdict were violent crimes in $17 \%$ of cases $(n=710)$. Other common categories of primary crimes were drug crimes $(32 \%, n=1,331)$, acquisitive crimes including theft, robbery, and other property crimes $(29 \%$, $\mathrm{n}=1,236)$, financial crimes $(4 \%, \mathrm{n}=185)$, “crimes against public activities" $(4 \%, \mathrm{n}=180)$, molestation of females $(3 \%$, $\mathrm{n}=132)$, weapon crimes $(2 \%, \mathrm{n}=97)$, other traffic crimes $(2 \%, n=89)$, driving under the influence of substances $(1 \%$, $\mathrm{n}=53)$, and smuggling $(1 \%, \mathrm{n}=57)$. Arson $(\mathrm{n}=39)$ and sexual crimes $(n=28)$ including rape and sexual molestation were the primary crimes $(<1 \%)$.

Lifetime history of substance use differed markedly in perpetrators of violent crime compared to all other criminal justice clients with substance use problems (Table 1). In violent perpetrators, several types of illicit drug use were less common than in perpetrators of drug crimes (heroin, cocaine, amphetamine, injecting drug use), as well as a history of psychiatric hospitalization, whereas alcohol binge drinking and sedatives were more common in the violent group. In comparison between violent and acquisitive crimes, the latter group was more likely to report heroin, cocaine, amphetamine, cocaine and injecting drug use, whereas no difference was seen for sedatives in this comparison, and binge drinking was more prevalent in the 
Table I Substance use pattern, previous psychiatric hospitalization, and demographic characteristics in main categories of crime binary comparisons with violent crime as category of reference (chi-square)

\begin{tabular}{|c|c|c|c|c|}
\hline & $\begin{array}{l}\text { Violent crime } \\
(n=7 \mid 0), n(\%)\end{array}$ & $\begin{array}{l}\text { Drug crime } \\
(n=I, 33 I), n(\%)\end{array}$ & $\begin{array}{l}\text { Acquisitive crime } \\
(n=1,236), n(\%)\end{array}$ & $\begin{array}{l}\text { Other crime } \\
(n=925), n(\%)\end{array}$ \\
\hline \multicolumn{5}{|l|}{ Problem substance use (>6 months) } \\
\hline Binge drinking & $4 I I(58)$ & $456(34)^{* * *}$ & $550(44)^{* * *}$ & $499(54)$ \\
\hline Heroin & $94(13)$ & $325(24)^{* * *}$ & $334(27)^{* * *}$ & $162(18)^{*}$ \\
\hline Other opioids & $92(13)$ & $169(13)$ & $224(18)^{* *}$ & $138(15)$ \\
\hline Cocaine & $89(13)$ & $256(19)^{* * *}$ & $214(17)^{* *}$ & $130(14)$ \\
\hline Amphetamine & $377(53)$ & $879(66) * * *$ & $800(65)^{* * *}$ & $614(66)^{* * *}$ \\
\hline Cannabis & $418(59)$ & $836(63) * * * *$ & $836(68) * * *$ & $510(55)$ \\
\hline Sedatives & $283(40)$ & $386(29) * * *$ & $525(42)$ & $304(33)^{* *}$ \\
\hline Injecting drug use & $284(40)$ & $726(55)^{* * *}$ & $704(57)^{* * *}$ & $497(54)^{* * *}$ \\
\hline Psychiatric hospitalization, ever & $126(18)$ & $147(||)^{* * *}$ & $212(17)$ & $184(20)$ \\
\hline Male gender & $653(92)$ & $1170(88)^{* *}$ & $1130(91)$ & $835(90)$ \\
\hline Homeless past 30 days prior to incarceration & $133(19)$ & $209(16)^{* * * *}$ & $346(28) * * *$ & $252(27)^{* * *}$ \\
\hline Mean age $(S D)^{1,2}$ & $32.6(10.18)$ & $35.9(10.21)^{* * *}$ & $30.5(8.4 I)^{* * *}$ & $34.7(9.40) * * *$ \\
\hline
\end{tabular}

Notes: 'Data missing for age in 11 cases, binge drinking in 65 cases, heroin in 12, other opioids in 27, sedatives in 39, cocaine in 17, amphetamine in 42, cannabis in 46, and injecting drug use in 17 cases, psychiatric hospitalization in 37, homelessness in 22 cases, and gender in 0 case. For all variables, missing data were assumed to be a negative answer, i.e., absence of substance use, hospitalization, and homelessness. ${ }^{2}$ Significance of comparison tested with student's $t$-test, not assuming normal distribution. ${ }^{*} p<0.05$; $* * p<0.01 ; * * * p<0.001 ; * * * * p<0.10$.

violent group. Compared to the remaining categories of main crimes, the violent group displayed higher prevalence of sedatives and lower prevalence of heroin, amphetamine, and injecting drug use. The violent group was significantly younger than the drug crimes group and the group sentenced with other crimes, but older than clients sentenced with acquisitive crimes.

\section{Adjusted results of factors associated with violent crime compared with all other crimes}

In the logistic regression analysis (comparing violent crime to all other categories of crime), a history of binge drinking, use of sedatives, and male gender were positively associated with violent crime, compared to all other clients. Use of heroin, amphetamine, cocaine, and injecting drug use were negatively associated with violent crime (Table 2).

\section{Descriptive findings of substance use, psychiatric hospitalization, and demographics: fatal crime versus non-fatal violent crime}

Within the group of perpetrators of violent crime $(n=710)$, subjects convicted for fatal violence differed from the rest of violent perpetrators, with respect to heroin use, amphetamine use, and homelessness, which were all less prevalent in the fatal violence group. However, the groups sentenced
Table 2 Variables associated with violent crime compared to all other crimes: a logistic regression including all subjects

\begin{tabular}{|c|c|}
\hline & $\begin{array}{l}\text { Adjusted odds ratio } \\
(95 \% \mathrm{Cl})\end{array}$ \\
\hline Binge drinking! & $1.84(1.55-2.18)^{*}$ \\
\hline Heroin' & $0.58(0.45-0.75)^{*}$ \\
\hline Other opioids' & $0.93(0.7|-| .2 I)$ \\
\hline Cocaine ${ }^{\prime}$ & $0.62(0.48-0.79)^{*}$ \\
\hline Amphetamine' & $0.64(0.52-0.78) *$ \\
\hline Cannabis' & $0.95(0.79-1.14)$ \\
\hline Sedatives' & $1.53(1.27-1.85)^{*}$ \\
\hline Injecting drug use' & $0.72(0.58-0.89)^{*}$ \\
\hline Psychiatric hospitalization & $1.15(0.92-1.43)$ \\
\hline Male gender & $1.23(0.91-1.66)$ \\
\hline Homeless & $0.86(0.69-1.07)$ \\
\hline Age (by year)' & $1.00(0.99-1.01)$ \\
\hline
\end{tabular}

Notes: ' Substance use variables refer to regular problem use for at least 6 months. ${ }^{*} p<0.05$.

with fatal and non-fatal violence did not differ with respect to psychiatric hospitalization, gender, or age (Table 3).

\section{Adjusted results of factors associated with fatal violent crime compared with non-fatal violent crime}

In the logistic regression analysis, comparing clients sentenced for fatal violence to those sentenced for non-fatal violence, age and (with marginal significance) sedatives were positively associated with fatal violence. Amphetamine, homelessness, and (with marginal significance) heroin were negatively associated with fatal violence (Table 4). 
Table 3 Substance use pattern, previous psychiatric hospitalization, and demographic characteristics - binary comparisons of fatal and non-fatal violent crime (chi-square)

\begin{tabular}{llll}
\hline & Fatal violence $(\mathbf{n}=\mathbf{1 6 4}), \mathbf{n}(\%)$ & Non-fatal violence (n=546), $\mathbf{n}(\%)$ & $\mathbf{p}$-value \\
\hline Problem substance use (>6 months) & & & \\
$\quad$ Binge drinking & $95(58)$ & $316(58)$ & 0.99 \\
Heroin & $14(9)$ & $80(15)$ & $0.04^{*}$ \\
Other opioids & $23(14)$ & $69(13)$ & 0.64 \\
Cocaine & $19(12)$ & $70(13)$ & 0.68 \\
Amphetamine & $75(46)$ & $302(55)$ & $0.03^{*}$ \\
Sedatives & $71(43)$ & $212(39)$ & 0.31 \\
Cannabis & $90(55)$ & $328(60)$ & 0.24 \\
Injecting drug use & $59(36)$ & $225(41)$ & 0.23 \\
Psychiatric hospitalization & $33(20)$ & $93(17)$ & 0.36 \\
Male gender & $149(91)$ & $504(92)$ & 0.55 \\
Homelessness & $18(11)$ & $115(21)$ & $<0.0 I^{* *}$ \\
Mean age & 33.8 & 32.3 & 0.10 \\
\hline
\end{tabular}

Notes: ${ }^{*} p<0.05 ; * *<<0.01$.

Table 4 Variables associated with fatal versus non-fatal violent crime: a logistic regression (including only clients sentenced with violent crime)

\begin{tabular}{|c|c|}
\hline & $\begin{array}{l}\text { Adjusted odds ratio } \\
(95 \% \mathrm{Cl})\end{array}$ \\
\hline Binge drinking' & $0.92(0.64-1.34)$ \\
\hline Heroin' & $0.52(0.27-1.01)^{* *}$ \\
\hline Other opioids' & $1.38(0.78-2.46)$ \\
\hline Cocaine ${ }^{\prime}$ & $0.95(0.54-1.68)$ \\
\hline Amphetamine' & $0.63(0.40-0.98)^{*}$ \\
\hline Cannabis' & $1.02(0.68-1.52)$ \\
\hline Sedatives ${ }^{\prime}$ & $1.48(0.98-2.22)^{* *}$ \\
\hline Injecting drug use' & $1.04(0.66-1.64)$ \\
\hline Psychiatric hospitalization & $1.19(0.75-1.88)$ \\
\hline Male gender & $0.95(0.49-1.82)$ \\
\hline Homeless & $0.48(0.27-0.83)^{*}$ \\
\hline Age (by year)' & $1.02(1.00-1.04)^{*}$ \\
\hline
\end{tabular}

Notes: 'Substance use variables refer to regular problem use for at least 6 months. $* p<0.05 ; * * p<0.10$.

\section{Discussion}

The present paper presents how substance use patterns differ across different categories of crime, in adult prisoners with substance use problems, and demonstrates the distribution of substances in violent criminals compared to those involved in other crimes, and further, how perpetrators of fatal violence differed from clients convicted for non-fatal violent crime. Several illicit substances were less common in violent offenders than in perpetrators of other crime categories. Differences from clients convicted for drug crimes and acquisitive crimes accounted for part of that difference, whereas in contrast, sedative use and alcohol binge drinking were more prevalent in violent offenders. Further, similar associations were seen for fatal violence; sedatives and illicit drugs were positively and negatively associated, respectively, with fatal violence in comparison to non-fatal violence. Thus, the substance use profile with sedating substances in perpetrators of violent crime, rather than illicit drugs of abuse, appeared to be more pronounced for perpetrators of fatal violence.

While all clients assessed in the present paper reported a primary substance of abuse, and hence, likely had a significant substance use problem, it may not be surprising that illicit drugs such as amphetamine, heroin, and cocaine are more frequently reported by clients sentenced for drug crimes. However, for the use of sedatives, which are known to be used concomitantly with severe illicit drug use, ${ }^{28}$ there was an association with violent crime, and within that subgroup an association with fatal violence. Thus, it may be argued that sedative drugs are at least more prevalent among substance users involved in violent crimes than among substance users involved in other crimes and that the use of sedative drugs may either contribute to the violent behavior or may share common characteristics with the risk factors of clients committing violent and fatal violent crimes.

While this is a comparison of substance use patterns in different types of crimes within a criminal justice sample with substance use problems, and specifically in Sweden, results cannot be generalized to the general population or to other geographical settings, and they cannot specifically address issues about how substances facilitate criminal acts and also cannot be generalized to prison populations with more female clients or regions with markedly different legislation. However, for the forensic setting, these results suggest important differences in the substance use patterns of clients, depending on the type of crime because of which they are subject to criminal justice interventions. Thus, for example, the challenges to meet in diagnostic and therapeutic work in 
the criminal justice system likely need to be highly individualized, and different challenges are faced for perpetrators of violent crime than for many other clients.

For alcohol, the findings of the present study are consistent with other data describing alcohol as a risk factor of violence. ${ }^{29,30}$ Also, Young et al demonstrated that in addition to attention deficit hyperactivity disorder, alcohol diagnosis predicted violent crime. ${ }^{31}$

There is some literature - although limited - on the potential link between benzodiazepines and violent crime, both from the present geographical setting and others. Haggard-Grann et al, in a paper from the present setting as here, not only confirmed the picture of alcohol consumption as a proximal risk factor of violent behavior but also showed that benzodiazepines in prescription doses did not increase the risk of violence, even demonstrating a lower risk. ${ }^{32}$ In contrast, a link between the use of sedatives (benzodiazepines) and violent behavior has been suggested from case studies, such as in the present geographical setting, ${ }^{33}$ and a recent review paper summarized the studies examining a potential link between benzodiazepines and violence. Despite a large number of studies addressing this issue in some way, study quality was generally low, and few high-quality studies address forensic populations, ${ }^{34}$ and dose-response associations have been difficult to interpret. ${ }^{34,35}$ Although benzodiazepines have been suggested as violence-enhancing drugs through a disinhibitory effect on human behavior, other data have shown that the increase in violence after benzodiazepine intake may be associated with preexisting personality factors, giving the substance a less pronounced role in the prediction of violent acts. ${ }^{36,37}$ The ASI interview in the version used at the time of the present study ${ }^{38}$ was unable to separate prescribed sedative use from overuse or illicit use of the medication. Previous findings, although not yet conclusive, have indicated violence-promoting effects of both lower doses, such as those prescribed, and higher doses which may be more typically a part of illicit drug use. Based on this, there may not clearly be a rationale for separating prescribed and nonprescribed intake of sedatives. ${ }^{7,34,35}$ However, the fact that the present study cannot separate illicit and licit use of sedatives is clearly a limitation. Despite this limitation, the actual use of sedatives was markedly more common in perpetrators of violent crime and even more so in fatal violence.

The relationship between substance use and violent behavior is complex and their close association is likely to be explained by both neurobiological mechanisms related to certain types of drugs and to social and contextual factors. ${ }^{7}$
In addition, these constructs are likely to share common risk factors.

For opiates, in the literature from other settings than the present, no consistent human data have indicated a link to aggressive behavior, and a higher degree of involvement in opiate users has been described to be more related to personality traits than to the substance per se. Likewise, for cannabis, cocaine, amphetamine, and hallucinogenic drugs, available data have not found a consistent increase in violent behavior. ${ }^{7}$ For cocaine, Buchanan et al identified an increase in violence in psychiatric outpatients related to cocaine specifically. ${ }^{39}$ An association in the same direction was not seen here, although the cocaine-using group is more limited in the Swedish setting than in many other countries. ${ }^{18}$

Apart from substance use variables assessed here, one limitation is clearly that the present study cannot provide data on other psychiatric conditions likely to cause violence As a mainly descriptive analysis of substance use patterns in different groups of criminals, it cannot make predictions about violent behavior among the general population or in substance users in comparison to non-users in the population. In the literature, several psychiatric problem variables and several contextual or background factors have been described to predict violent behavior. These factors may include an aggressive childhood environment and family history of violence and substance use disorders, ${ }^{5}$ and with the individual's own psychiatric background characteristics including conduct disorder and hyperactivity. ${ }^{40}$ It has been demonstrated that a very small proportion of the general population is responsible for a very large proportion of violent crimes in the community, ${ }^{11}$ and that substance use disorders as a group, as well as several neurodevelopmental and psychiatric disorders, contribute to these behaviors. Here, one covariate was a lifetime history of psychiatric hospitalization, which is likely to indicate a certain level of psychiatric problems over the threshold where patients are not likely to be treated exclusively in an outpatient setting. The ASI contains symptom variables describing self-reported psychiatric symptoms during the past 30 days (prior to incarceration) and previously. Here, in a control analysis, all included variables were run against lifetime history of depression, anxiety, suicide attempts, hallucinations, and difficulties thinking, remembering, and concentrating. This yielded the same statistical associations with violent crime and with fatal violence as in the original analyses. With the exception of anxiety showing a marginally significant association with violent crime, none of these self-reported 
symptom variables were associated with violent crime. As these variables are self-reported, conclusions are difficult to draw about their potential association with violent crime. This calls for study designs where actual psychiatric diagnoses can be followed and run against violent and other criminal behaviors, and the lack of such diagnostic data is a limitation of the present prison material.

The present work also has other limitations: data on substance use, psychiatric hospitalization, and homelessness are self-reported, although within the structure of a well-established interview instrument and in dialogue with trained interviewers. Also, included data are cross-sectional and substance use variables described here refer to lifetime use, although specified as regular and with a duration of at least half a year. Clients are included in the study because of a significant substance-related problem, such that it can be assumed that substance use had been clearly problematic in close proximity to the crime committed and prior to incarceration; however, substance use may have varied over time and an absolute link cannot be established between the actual use of a substance and crimes committed. Instead, in a relatively large data material, we have aimed to describe how types of crime vary across different patterns of substance use and also to demonstrate how substance use problems likely to require treatment differ across types of crime.

Also, although substance use data do not refer to the most recent period of time prior to incarceration, memory bias cannot be excluded. Also, the time interval until the interview was variable for individual reasons, and time from arrival to the unit where the interview took place, to the actual interview, was less than 30 days in $55 \%$ of cases, less than 90 days in $84 \%$, and less than a year in $97 \%$. Again, substance use data and data on lifetime history of psychiatric hospitalization were supposed to demonstrate the problem burden of an individual over time, rather than specifically prior to incarceration, but a potentially negative effect of time on the reliability of self-reported data cannot be disregarded. In addition, as the data used here were collected between 2001 and 2006, it cannot be excluded that associations and interpretations studied here may have undergone some change, e.g., due to possible policy changes in more recent years.

Another limitation is - as in any analysis of criminal verdicts - that data reflect the type of crime for which the individual was sentenced, rather than all criminal behavior. Here, it was assumed that self-reported data on criminal behavior may have a weaker reliability and that the focus on the main crime in the verdict would reflect objective information about the most severe crime known and included in the verdict. Also, the analysis of the main crime - rather than subjective data on all-type criminality - was chosen in order to enable a study of distinctly separate categories of crime.

The present study addressed a data material of prisoners, which may not be generalizable to subjects who commit crimes that are not likely to lead to prison; however, the organizational structures of correctional institutions are very diverse between countries. Likewise, the distinction between prison and forensic psychiatry is likely to be very different in different settings. In the present study, despite high prevalence of psychiatric morbidity, it can be assumed that included subjects do not suffer from a diagnosed severe mental illness, such as a psychotic disorder, as these conditions typically lead to forensic psychiatric treatment as a response to criminal acts. This may limit generalizability of these findings to settings where prison and court-ordered psychiatric treatments are less separated. In addition, a large majority of the prisoners included here were men, such that generalizability may be limited to populations of female prisoners with substance use.

The present study may further support the need for large-scale and high-quality clinical studies of how benzodiazepines and other sedatives affect aggressive behavior. Also, in addition, the results may have clinical implications for evaluation and treatment of substance use disorders in prisoners. Studies on substance use disorders treatment for prevention of crime have focused on opiate dependence ${ }^{41}$ and amphetamine.$^{42}$ While other types of crime are more clearly associated with drug crime and acquisitive crime in the present study, the associations with binge alcohol drinking and sedatives rather call for increased focus on the treatment of these conditions in the criminal justice setting. Further studies are needed addressing how treatment of alcohol and sedative use disorders may influence crime and criminal recidivism.

\section{Conclusion}

In this sample of prisoners with substance use problems, traditional illicit drug use may be less common in violent perpetrators than in clients sentenced for other crime, and in contrast, sedatives use and alcohol binge drinking were more prevalent in violent offenders. Among the subgroup of violent offenders with substance use, sedatives may be positively associated and illicit drugs negatively associated with fatal violence.

\section{Acknowledgments}

The authors are grateful to the staff of the Swedish Prison and Probation Service for the interview data collection and to the statistical register service of the Swedish Prison and Probation Service for their help with the register data collection. 


\section{Author contributions}

$\mathrm{VJ}$ and $\mathrm{AH}$ jointly planned the study. AH was the principal investigator of the overall project. VJ carried out statistical analyses and wrote the first draft of the paper. AH finalized the writing of the manuscript. Both authors contributed toward data analysis, drafting and revising the paper and agree to be accountable for all aspects of the work.

\section{Disclosure}

AH has received speaker fees and travel reimbursements for conference contributions (from Lundbeck in 2011 and 2012) and for teaching purposes (arranged by Schering-Plough, Reckitt-Benckiser, Skåne County, and Uppsala University on four occasions until 2011). He holds a researcher position at Lund University, Sweden, in collaboration with the Swedish governmental monopoly for gambling (Svenska spel) as part of that body's government-supported responsibility for research and prevention in the pathological gambling field. These collaborations are unrelated to the present paper. The authors report no other conflicts of interest in this work.

\section{References}

1. Bennett T, Holloway K. The causal connection between drug misuse and crime. Br J Criminol. 2009;49:513-531.

2. Fazel S, Bains, Doll H. Substance abuse and dependence in prisoners: a systemic review. Addiction. 2006;101:181-191.

3. Pulay AJ, Dawson DA, Hasin DS, et al. Violent behaviour and DSM-IV psychiatric disorders: results from the national epidemiologic survey on alcohol and related conditions. J Clin Psychiatry. 2008;69:12-22.

4. Boden JM, Fergusson DM, Horwood LJ. Alcohol misuse and violent behaviour: findings from a 30-year longitudinal study. Drug Alcohol Depend. 2012;122:135-141.

5. Boles MS, Miotto K. Substance abuse and violence: a review of the literature. Aggression Violent Behav. 2003;8:155-174.

6. Grann M, Fazel S. Substance misuse and violent crime: Swedish population study. BMJ. 2004;328:1233-1234.

7. Hoaken PN, Stewart SH. Drugs of abuse and the elicitation of human aggressive behaviour. Addict Behav. 2003;28:1533-1554.

8. Lundholm L, Häggård U, Möller J, Hallqvist J, Thiblin I. The triggering effect of alcohol and illicit drugs on violent crime in a remand prison population: a case crossover study. Drug Alcohol Depend. 2013;129:110-115.

9. Håkansson A, Berglund M. All-cause mortality in criminal justice clients with substance use problems - a prospective follow-up study. Drug Alcohol Depend. 2013;132:499-504.

10. Ericsson E, Brådvik L, Håkansson A. Mortality, causes of death and risk factors for death among primary amphetamine users in the Swedish criminal justice system. Subst Use Misuse. 2014;49:262-269.

11. Falk Ö, Wallinius M, Lundström S, Frisell T, Anckarsäter H, Kerekes N. The $1 \%$ of the population accountable for $63 \%$ of all violent crime convictions. Soc Psychiatry Psychiatr Epidemiol. 2014;49:559-571.

12. Moberg T, Stenbacka M, Tengström A, Jönsson EG, Nordström P, Jokinen J. Psychiatric and neurological disorders in late adolescence and risk of convictions for violent crime in men. BMC Psychiatry. 2015;15:299.

13. Van Dorn R, Volavka J, Johnson N. Mental disorder and violence: is there a relationship beyond substance use. Soc Psychiatry Psychiatr Epidemiol. 2012;47:487-503.

14. Chang Z, Lichtenstein P, Långström N, Larsson H, Fazel S. Association between prescription of major psychotropic medications and violent reoffending after prison release. JAMA. 2016;316:1798-1807.
15. Rognli EB, Berge J, Håkansson A, Bramness J. Does the pattern of amphetamine use prior to incarceration predict later psychosis? A longitudinal study of amphetamine users in the Swedish criminal justice system. Drug Alcohol Depend. 2014;143:219-224.

16. McCabe SE, Boyd CJ, Teter CJ. Subtypes of nonmedical prescription drug misuse. Drug Alcohol Depend. 2009;102:63-70.

17. Håkansson A. Overdoses, Suicidal Behaviour and Clinical Characteristics in Heavy Drug Users. Studies in the Criminal Justice System. [doctoral dissertation], Lund, Sweden: Lund University. Available from: http://portal.research.lu.se/portal/files/3863206/1275689.pdf. Accessed September 28, 2017.

18. Håkansson A, Schlyter F, Berglund M. Characteristics of primary amphetamine users in Sweden. A criminal justice population examined with the Addiction Severity Index (ASI). Eur Addict Res. 2009;15:10-18.

19. Stewart D, Gossop M, Marsden J, Rolfe A. Drug misuse and acquisitive crime among clients recruited to the National Treatment Outcome Research Study (NTORS). Criminal Behav Mental Health. 2000;10:10-20.

20. Gossop M, Trakada K, Stewart D, Witton J. Reductions in criminal convictions after addiction treatment: 5-year follow-up. Drug Alcohol Depend. 2005;79:295-302.

21. Tengvald K, Andrén A, Bergman H, et al. Implementing the Addiction Severity Index (ASI) in Swedish human services sectors: experiences, problems and prospects. J Subst Use. 2014;9:163-171.

22. Håkansson A, Berglund M. Risk factors for criminal recidivism - a prospective follow-up study in prisoners with substance abuse. $B M C$ Psychiatry. 2012;12:111.

23. McLellan AT, Cacciola JC, Alterman AI, et al. The Addiction Severity Index at 25: origins, contributions and transitions. Am J Addict. 2006;15: 113-124.

24. McLellan AT, Kushner H, Metzger D, et al. The fifth edition of the Addiction Severity Index. J Subst Abuse Treat. 1992;9:199-213.

25. McLellan AT, Luborsky L, Woody GE, O’Brien P. An improved diagnostic evaluation instrument for substance abuse patients. The Addiction Severity Index. J Nerv Ment Dis. 2006;168:26-33.

26. Friedman A, Utada A. A method for diagnosing and planning the treatment of adolescent drug abusers (the Adolescent Drug Abuse Diagnosis [ADAD] instrument). J Drug Educ. 1989;19:285-312.

27. Tabachnick BG, Fidell LS. Using Multivariate Statistics. 5th ed. Boston: Allyn and Bacon; 2007.

28. Brands B, Blake J, March DC, Sproule B, Jeyapalan R, Li S. The impact of benzodiazepine use on methadone maintenance treatment outcomes. J Addict Dis. 2008;27:37-48.

29. Murdoch D, Pihl RO, Ross D. Alcohol and crimes of violence: present issues. Int J Addict. 1990;25:1065-1081.

30. Plattner A, Giger J, Bachmann F, et al. Psychopathology and offense types in detailed male juveniles. Psychiatry Res. 2012;198:285-290.

31. Young S, Wells J, Gudjonsson GH. Predictors of offending among prisoners: the role of attention-deficit hyperactivity disorder and substance use. J Psychopharmacol. 2011;25:1524-1532.

32. Häggård-Grann U, Hallqvist $J$, Långström N, Möller J. The role of alcohol and drugs in triggering criminal violence: a case-crossover study. Addiction. 2006;101:100-108.

33. Dåderman AM, Fredriksson B, Kristiansson M, et al. Violent behavior, impulsive decision-making, and anterograde amnesia while intoxicated with flunitrazepam and alcohol or other drugs: a case study in forensic psychiatric patients. J Am Acad Psychiatry Law. 2002;30:238-251.

34. Albrecht B, Staiger PK, Hall K, Miller P, Best D, Lubman DI. Benzodiazepine use and aggressive behaviour: a systematic review. Aust NZ J Psychiatry. 2014;48:1096-1114.

35. Albrecht B, Staiger PK, Hall K, Kambouropoulos N, Best D. Motivational drive and alprazolam misuse: a recipe for aggression? Psychiatry Res. 2016;240:381-389.

36. Rothschild AJ. Disinhibition, amnestic reactions, and other adverse reactions secondary to triazolam: a review of the literature. J Clin Psychol. 1992;53(Suppl 12):69-79.

37. Ben-Porath DD, Taylor SP. The effects of diazepam (valium) and aggressive disposition on human aggression: an experimental investigation. Addict Behav. 2002;27:167-177. 
38. Öberg D, Zingmark D, Sallmén B. ASI-X V 2.02. 2002. Available from: http://www.emcdda.europa.eu/attachements.cfm/att_23587_EN_EuropAsi\%20Interview\%20form\%20EN.pdf. Accessed January 01, 2018.

39. Buchanan A, Nich C, Douglas KS, Babuscio T, Easton CJ. Risk factors of violence during a 4-week period in a psychiatric outpatient population. J Nerv Mental Dis. 2013;201:1021-1026.

40. Hofvander B, Ståhlberg O, Nydén A. Life history of aggression scores are predicted by childhood hyperactivity, conduct disorder, adult substance abuse, and low cooperativeness in adult psychiatric patients. Psychiatry Res. 2011;185:280-285.
41. Bukten A, Skurtveit S, Gossop M, et al. Engagement with opioid maintenance treatment and reductions in crime: a longitudinal national cohort study. Addiction. 2011;107:393-399.

42. Konstenius M, Jayaram-Lindström N, Guterstam J, Beck O, Philips B, Franck J. Methylphenidate for attention deficit hyperactivity disorder and drug relapse in criminal offenders with substance dependence: a 24-week randomized placebo-controlled trial. Addiction. 2013;109:440-449.

\section{Publish your work in this journal}

Substance Abuse and Rehabilitation is an international, peer-reviewed, open access journal publishing original research, case reports, editorials, reviews and commentaries on all areas of addiction and substance abuse and options for treatment and rehabilitation. The manuscript management system is completely online and includes a very quick and fair peer-review system. Visit http://www.dovepress.com/testimonials.php to read real quotes from published authors. 